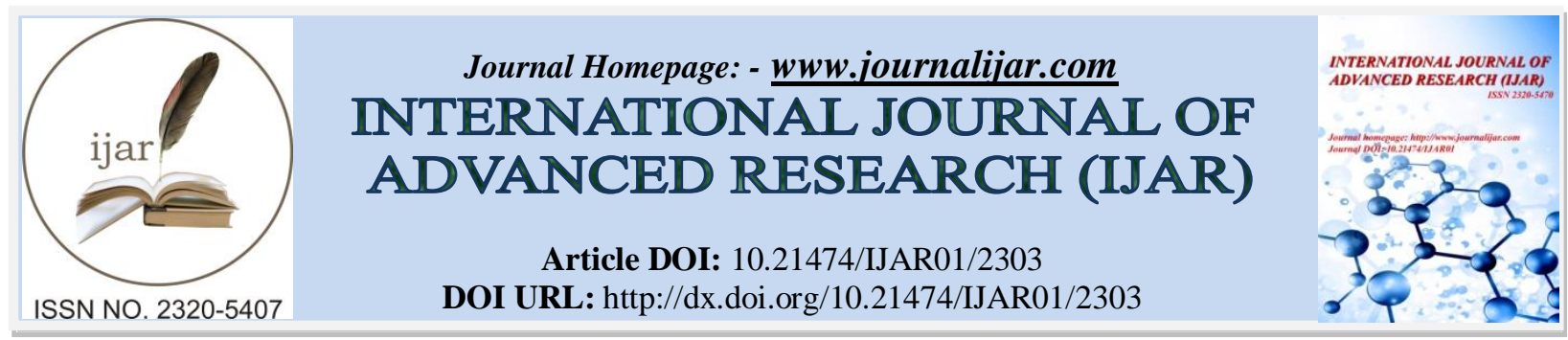

RESEARCH ARTICLE

\title{
HISTOPATHOLOGICAL STUDY OF NON NEOPLASTIC LESIONS OF CERVICAL LYMPH NODES.
}

"Inamdar A. A. ${ }^{1}$, Patil R. S. ${ }^{2}$, Verma $A^{1}$, Ghatge $R M^{1}$, Gupta $S^{1}$ and Sujata $\mathbf{N}^{1}$.

1. Post graduate student, Department of Pathology, D.Y. Patil Medical College, Kolhapur.

2. Associate Professor, Department of Pathology, D.Y. Patil Medical College, Kolhapur.

\section{Manuscript Info}

Manuscript History

Received: 29 September 2016

Final Accepted: 30 October 2016

Published: November 2016

Key words:-

Cervical lymph nodes, Non neoplastic

\begin{abstract}
Lymph node diseases are showing rising trend worldwide. A number of studies have been done in order to know the magnitude of problem. Cervical lymphadenopathy is one of the commonest clinical presentations. The involvement of lymph node by non neoplastic conditions is much more common than the neoplastic processes. The knowledge of the pattern of lymphadenopathy in a given geographical region is essential for making a confident diagnosis or suspecting a disease.Though fine needle aspiration cytology is commonly used to establish the etiological diagnosis, excision biopsy and histopathology of the lymph node remains the "gold standard" for diagnosis of lymphadenopathy. The present study focuses on most common nonneoplastic lesions of cervical lymph nodes and their histopathological diagnosis.
\end{abstract}

Copy Right, IJAR, 2016,. All rights reserved.

\section{Introduction:-}

Lymphadenopathy is defined as an abnormality in the size or character of lymph node caused by a vast array of disease processes, whose broad categories are Malignancies, Infections, Autoimmune disorders, Miscellaneous and unusual conditions, and Iatrogenic causes ${ }^{1}$.Head and neck lymphadenopathy represents $55 \%$ of all lymphadenopathies. It is usually of benign etiology, most commonly viral infections, especially in children ${ }^{2}$.

Cervical lymphadenopathy is one of the commonest clinical presentations. Localized cervical lymphadenopathy is lymph node enlargement that is restricted to cervical area $^{3}$. The involvement of lymph node by non-neoplastic conditions is much more common than the neoplastic processes ${ }^{1}$. Though fine needle aspiration cytology is commonly used to establish the etiological diagnosis, excision biopsy and histopathology of the lymph node remains the "gold standard" for diagnosis of lymphadenopathy".

Non malignant causes of lymphadenopathy are numerous and diverse ranging from infections such as tuberculosis, brucellosis, mononucleosis syndromes and cat scratch disease; extending to connective tissue disease such as systemic lupus erythematosus, rheumatoid arthritis; or it may be iatrogenic as a result of certain drug intake such as phenytoin, carbamazepine, captopril, allopurinol and atenolol ${ }^{5}$.

In patients presenting with peripheral lymphadenopathy, excision biopsy of the most accessible lymph node provides material to establish an early diagnosis, and is important in the management of these patients ${ }^{6}$.

In a large number of patients, the causes of lymphadenopathy remain undiagnosed ${ }^{7}$.

Corresponding Author:- Inamdar A. A.

Address:- Post graduate student, Department of Pathology, D.Y. Patil Medical College, Kolhapur. 
As there is a paucity of information on the spectrum of diseases affecting lymph nodes from this region. Hence this study was undertaken with the aim of evaluating the spectrum of histopathological diagnosis of non neoplastic lesions in cervical lymph node biopsies.

\section{Materials and Methods:-}

This was a prospective study undertaken in the Department of Pathology, D. Y. Patil Medical College, Hospital and Research centre, Kolhapur, from May 2014 to April 2016. From all the cervical lymph node biopsies received at the department of pathology, only Non neoplastic lesions like tuberculosis, acute and chronic nonspecific lymphadenitis, chronic specific lymphadenitis such as bacterial, viral and fungal, reactive lymphadenitis and other specific lesions such as Kikuchi-Fujimoto disease, Castleman disease, Kimura disease, Rosai-Dorfman Disease and Cat scratch disease etc. were included in this study. Neoplastic lesions of cervical lymph nodes both primary and secondary were excluded from this study. Specimens were fixed in $10 \%$ formalin and were processed through series of ascending grades of alcohol for dehydration. Clearing was done with the help of acetone. Tissue embedding was done in molten paraffin wax. Wax blocks were made using Leuckhart's mould. Thin sections of three to four microns were cut, slides were prepared and stained by Haematoxylin and Eosin stain. Special stains such as ZN stain and PAS stain were used wherever required.

\section{Results:-}

In present study of 100 cases, 57 cases (57\%) were females and 43 cases $(43 \%)$ were males with male to female ratio of 1: 1.32 suggesting female preponderance (Table 1). Majority of the cases had age between 21-30 years (28 cases, $28 \%$ ) followed by 31 to 40 years ( 24 cases, 24\%), 11 to 20 years (22 cases, 22\%), 41 to 50 years (10 cases, $10 \%), 01$ to 10 years ( 9 cases, 9\%), 51 to 60 years ( 4 cases, 4\%), 61-70 years ( 2 cases, 2\%) and the least being more than 70 years (1 case, 1\%)(Table 2). Majority were diagnosed as Tuberculous lymphadenitis (46 cases, 46\%), followed by Chronic nonspecific lymphadenitis (36 cases, 36\%), Kikuchi lymphadenopathy (8 cases, $8 \%$ ), Kimura lymphadenopathy (2 cases, 2\%), Toxoplasma lymphadenitis (2 cases, 2\%), Sinus histiocytosis with massive lymphadenopathy (2 cases, 2\%), Human Immunodeficiency Virus Lymphadenitis (1 case, 1\%), Castleman lymphadenopathy (1 case, $1 \%)$, Cryptococcus lymphadenitis (1 case, 1\%) and Dermatopathic lymphadenopathy (1 case, $1 \%$ )(Table 3).

Table 1:- Sex wise distribution of Non neoplastic lesions of cervical lymph nodes.

\begin{tabular}{|l|l|l|}
\hline \multirow{2}{*}{ Sex } & Distribution(n=100) & Percentage \\
\cline { 2 - 3 } & Number & 43 \\
\hline Male & 43 & 57 \\
\hline Female & 57 & 100 \\
\hline Total & 100 & \\
\hline
\end{tabular}

$\mathrm{n}=$ Number of cases

Table 2:- Age wise distribution of Non neoplastic lesions cervical lymph nodes.

\begin{tabular}{|l|l|l|}
\hline Age & Non-neoplastic lesions & Percentage \\
\hline$<10$ & 9 & 9 \\
\hline $11-20$ & 22 & 22 \\
\hline $21-30$ & 28 & 28 \\
\hline $31-40$ & 24 & 24 \\
\hline $41-50$ & 10 & 10 \\
\hline $51-60$ & 4 & 4 \\
\hline $61-70$ & 2 & 2 \\
\hline$>71$ & 1 & 1 \\
\hline otal & 100 & 100 \\
\hline
\end{tabular}


Table 3:- Incidence of Non neoplastic lesions of cervical lymph nodes.

\begin{tabular}{|l|l|l|}
\hline Name of lesion & No. of cases & Percentage \\
\hline Tuberculous lymphadenitis & 46 & 46 \\
\hline Chronic nonspecific lymphadenitis & 36 & 36 \\
\hline Kikuchi Lymphadenopathy & 8 & 8 \\
\hline Kimura Lymphadenopathy & 2 & 2 \\
\hline Toxoplasma lymphadenitis wistiocytosis massive & 2 & 2 \\
\hline $\begin{array}{l}\text { Sinus Im } \\
\text { lymphadenopathy }\end{array}$ & 2 & 2 \\
\hline $\begin{array}{l}\text { Human Irus } \\
\text { Lymphadenitis }\end{array}$ & 1 & 1 \\
\hline Castleman Lymphadenopathy & 1 & 1 \\
\hline Cryptococcus Lymphadenitis & 1 & 1 \\
\hline Dermatopathic Lymphadenopathy & 1 & 1 \\
\hline Total & 100 & 100 \\
\hline
\end{tabular}

Figure 1:- Tuberculous lymphadenitis: Section shows large area of caseous necrosis surrounded by epithelioid cells, Langhans type of giant cell and small lymphocytes (H\&E stain; X10).

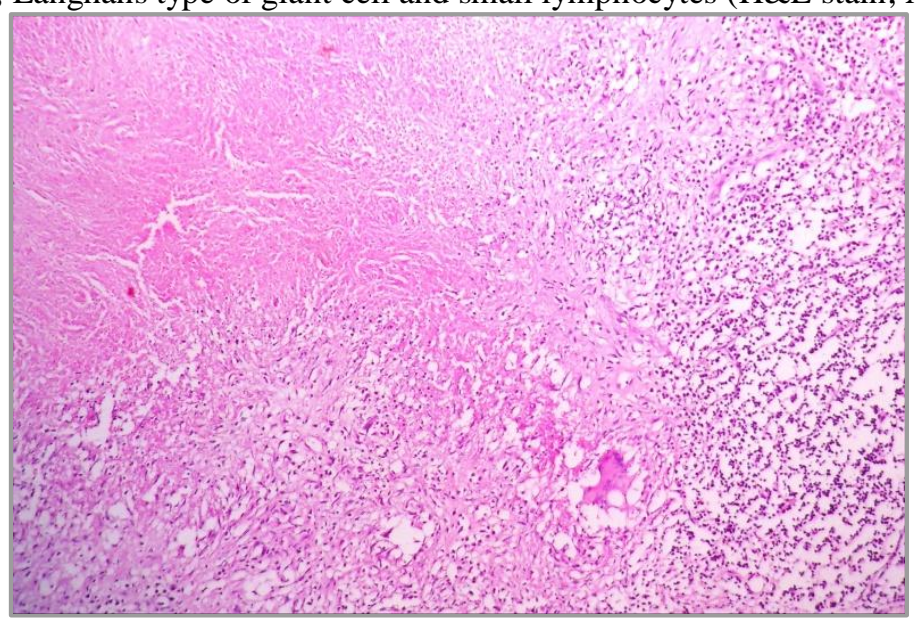

Figure 2:- Kikuchi lymphadenopathy: Section shows irregularly shaped area of necrosis consisting of bright eosinophilic fibrinoid deposits and apoptotic cells (H\&E stain; X40).

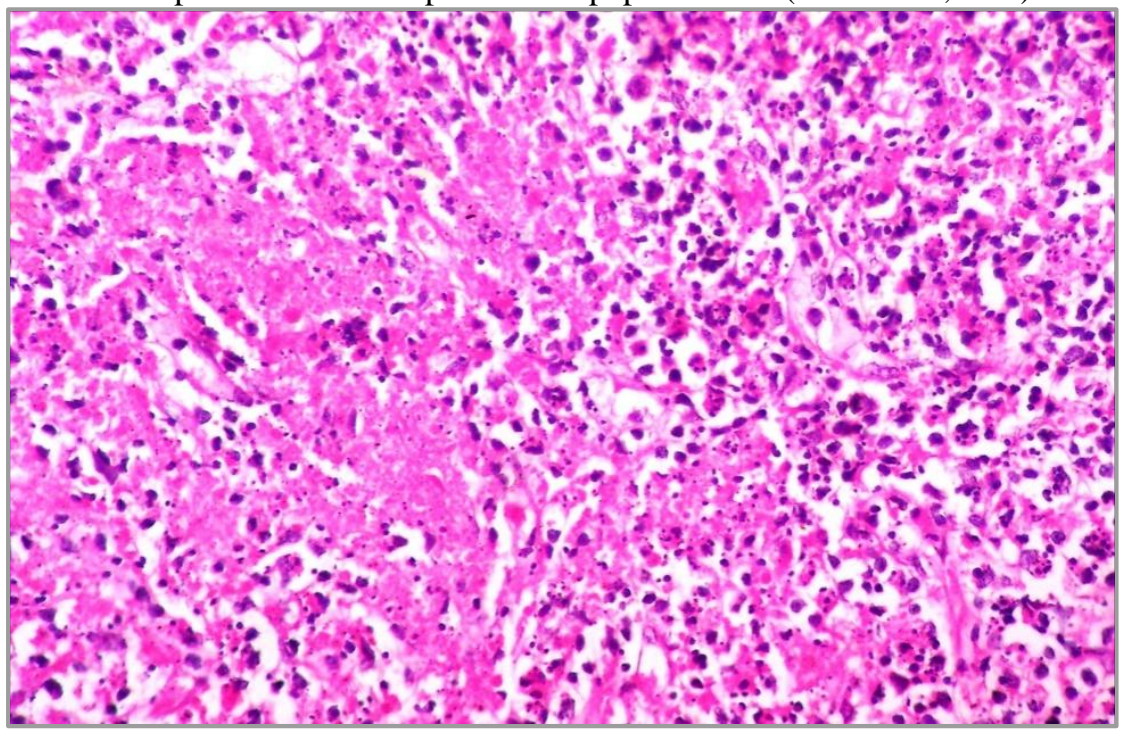


Figure 3:- Castleman lymphadenopathy: Section shows small germinal centre with concentric rings of small lymphocytes giving onion skin pattern (H\&E stain; X40).

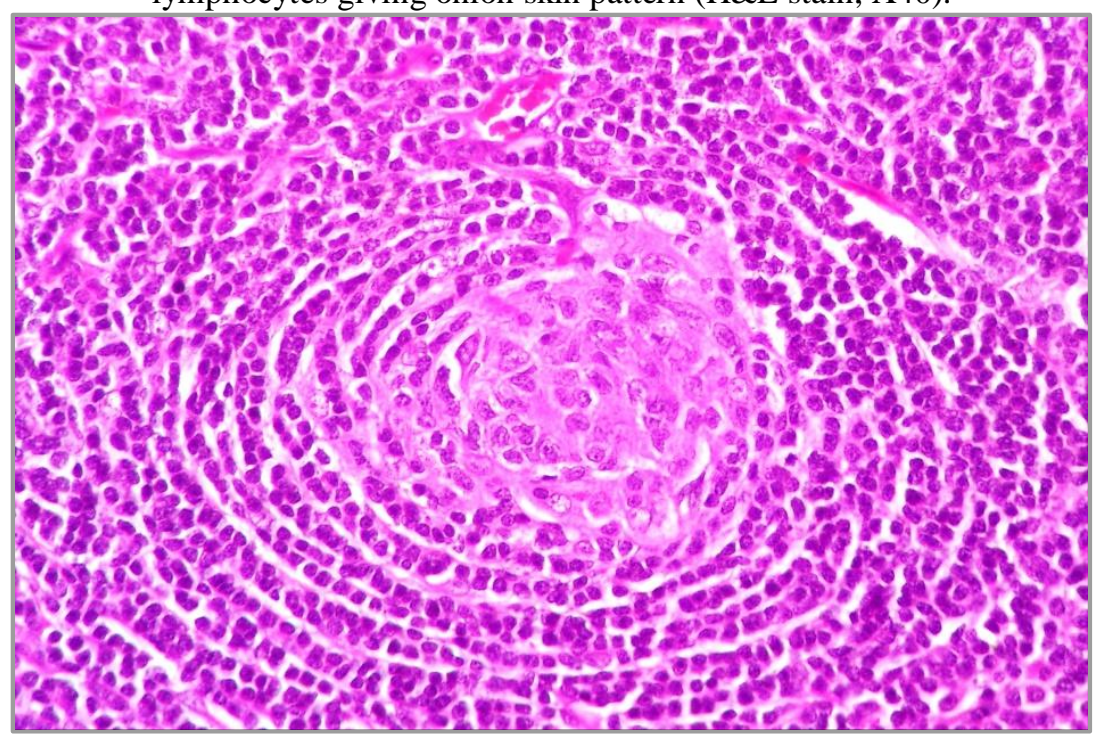

Figure 4:- Dermatopathic Lymphadenopathy: Section shows histiocytes containing phagocytosed melanin

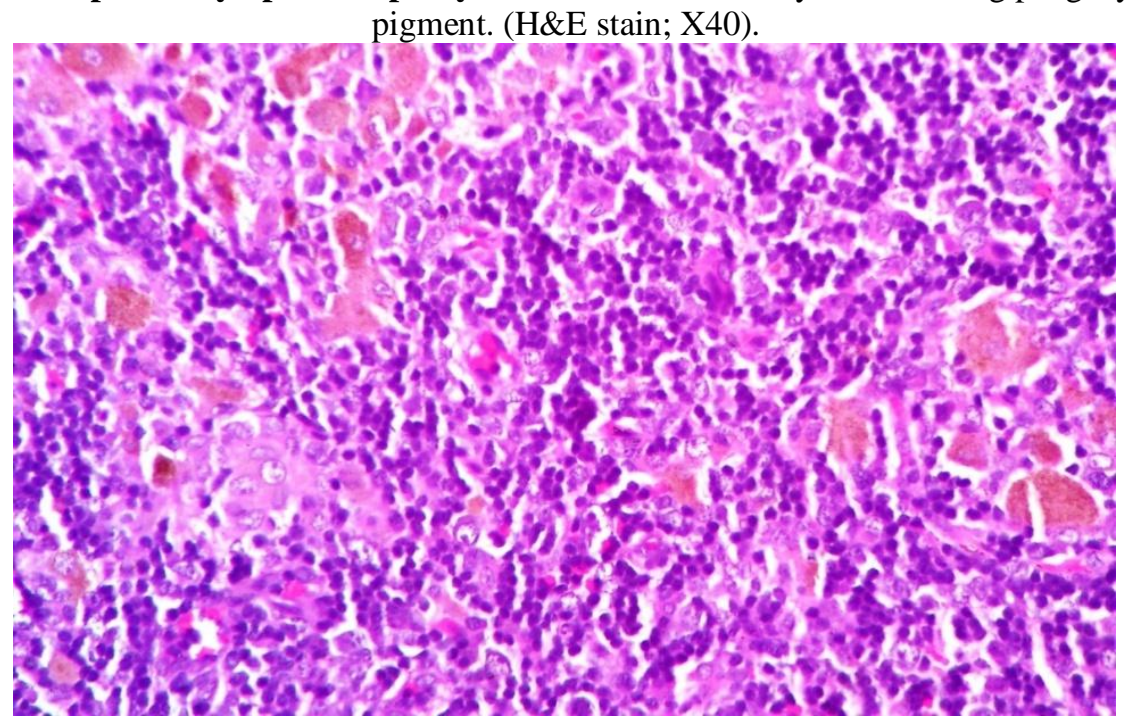

\section{Discussion:-}

Lymph node enlargement may occur because of proliferation of cells of the lymphocyte and monocyte-macrophage system usually in response to antigenic stimulus or infiltration by inflammatory cells in infections involving lymph nodes (lymphadenitis). Analysis of lymphadenopathy in primary care practice has shown that more than two-third of patients have non-specific causes or upper respiratory illnesses (viral or bacterial), and less than $1 \%$ have malignancy ${ }^{1}$.

In Present study, out of 100 cases 43 were males (43\%) and 57 were females (57\%). Female predominance was observed with male to female ratio of 1:1.3, (Table 1; Graph 1). Other studies such as Rehman A et al ${ }^{8}$ and Vemulapalli $\mathrm{N} \mathrm{K}$ et $\mathrm{al}^{9}$ also recorded female preponderance except Paliwal U K et al ${ }^{10}$ which shows slight male preponderance with male to female ratio of 1.04:1.

In the present study of 100 cases, majority (28 cases, 28\%) of the cases belonged to 21 to 30 years of age group. Rehman $\mathrm{A}$ et $\mathrm{al}^{8}$, also found similar result, with most of the patients between $2^{\text {nd }}$ and $3^{\text {rd }}$ decade. While Paliwal U K et $\mathrm{al}^{10}$ and Vemulapalli $\mathrm{N} \mathrm{K}$ et al ${ }^{9}$ reported $1^{\text {st }}$ and $2^{\text {nd }}$ decade as the commonest age group in their studies. 
In present study, Tuberculous lymphadenitis was the predominant lesion, (46 cases, $46 \%)$. This observation is nearly comparable with Rehman A et $\mathrm{al}^{8}$ and Vemulapalli $\mathrm{N} \mathrm{K}$ et $\mathrm{al}^{9}$ who reported highest incidence of tuberculous lymphadenitis in their study as $50.61 \%$ and $68 \%$ respectively. While Moor J W et al ${ }^{11}$ reported incidence of chronic nonspecific lymphadenopathy as highest being $50.83 \%$.

In present study, incidence of chronic nonspecific lymphadenitis was 36 cases (36\%). We also reported 8 cases (8 $\%$ ) of Kikuchi lymphadenopathy. This finding is nearly comparable with Moor J W et al ${ }^{11}$ and Rehman A et al ${ }^{8}$ who reported $4.16 \%$ and $3.70 \%$ respectively.

In present study, incidence of toxoplasma lymphadenitis was 2 cases (2\%), which nearly comparable with study done by Moor $\mathrm{J} \mathrm{W}$ et al ${ }^{11}$ being $1.66 \%$. Other studies did not report any cases of toxoplasma lymphadenitis.

In present study we also reported Kimura lymphadenopathy and Sinus histiocytosis with massive lymphadenopathy amounting 2\% each, Human Immunodeficiency Virus Lymphadenitis, Castleman lymphadenopathy, Cryptococcus Lymphadenitis and Dermatopathic lymphadenopathy amounting $1 \%$ each. These lesions were not seen in other studies. Other lesions found in their studies, which were not reported in present study, were Sarcoidosis, SLE, foreign body reaction, abscess, Cat-Scratch Lymphadenitis.

\section{Conclusion:-}

Cervical lymphadenopathy is one of the commonest clinical presentations of patients, attending the outpatient and inpatient departments. Etiology varies various infectious agents such as viruses and microbes to inflammatory conditions and malignant conditions. Though FNAC is the first choice of cervical lymphadenopathy biopsy remains gold standard for the complete diagnosis because FNAC at some times may be inconclusive or sometimes antibiotic therapy does not resolve the patient condition.

Of the 100 non-neoplastic cases studied majority were diagnosed as Tuberculous lymphadenitis even though geographical distribution and socio economic status are better in this area. This was followed by chronic nonspecific lymphadenitis, Kikuchi lymphadenopathy which was more common in females. Other lesions were Kimura lymphadenopathy, Sinus histiocytosis with massive lymphadenopathy, Toxoplasma lymphadenitis, HIV lymphadenitis, Castleman lymphadenopathy, Cryptococcus lymphadenitis and Dermatopathic lymphadenopathy.

To conclude, we came across various Non neoplastic cervical lymph node lesions in biopsy specimens and definitely biopsy is useful in management of various Non neoplastic diseases of cervical lymph nodes.

\section{Acknowledgment:-}

I would like to express gratitude and sincere thanks to Dr. (Mrs) S. S. More, Dr. R. S. Patil, Dr. P. V. Purohit, Dr. D. G. Paricharak, Dr. P. J. Shinde, Dr. (Mrs) A. P Shinde and Dr. Jaydeep Pol for their help and guidance during my study.

\section{References:-}

1. Chabra S, Mohan H, Bal A. A Retrospective Histological Evaluation of Non-neoplastic Superficial Lymphadenopathy.The Internet Journal of Internal Medicine. 2005; 6(1): 1-5.

2. Stefan L, Goran M, Jovana Ž. Palpable Lymphadenopathy in Primary Care. Scientific Journal of the Faculty of Medicine in Niš 2011;28(1):17-23.

3. Rama S, Aruna B, Adahra P B, Ankita S, Jaydip D. Comparative study of Cyto and Histopathology in Diagnosing Cervical Lymphnodal lesions. International Journal of Current Medical Research. 2015;4(11): 38693.

4. Panchal J. and Pushpalatha P. Spectrum of pathologic lesions in superficial lymph node biopsies $-\mathrm{A}$ one and half year study. IJBAR. 2014;5(09):435-38.

5. Abdullah A. A, Mohamed Z. K. Clinical approach to lymphadenopathy. JK Practitioner. 2011;16(1-2):1-8.

6. Alladi M, Reddy M. K, Phaneendra B. V, Abha C. Aetiology of peripheral lymphadenopathy in adults: Analysis of 1724 cases seen at a tertiary care teaching hospital in southern India. The National Medical Journal of India. 2007;20(2):78-80.

7. Jean-Marc R, Hubert L, Michel Z, Jean-Michel T, Gérard M, Pascal-Alexandre T. et al. Lymph Node Biopsy Specimens and Diagnosis of Cat-scratch Disease. Emerging Infectious Diseases. 2006;12(9):1338-44. 
8. Rehman M. A, Biswas M A, Siddika S T. Histomorphological Pattern of Cervical Lymphadenopathy. J Enam Med Col 2013; 3(1): 13-7.

9. Vemulapalli N K, Chitumalla P K. Study of Cervical Lymphadenitis, Correlation between Clinical Features, FNAC and Histopathology of Cervical Lymphadenitis. International Journal of Contemporary Medical Research. 2016; 3(8): 2231-34.

10. Paliwal U K, Nigam S K. Diagnostic Accuracy of Fine Needle Aspiration Cytology In Cervical Lymph Nodes with Histopathological Correlation. Journal of Evolution of Medical and Dental Sciences. 2013; 2(32): 5936-42.

11. Moor J W, Murray P, Inwood J, Gouldesbrough D, Bem C. Diagnostic biopsy of lymph nodes of the neck, axilla and groin: rhyme, reason or chance? Ann R CollSurgEngl 2008; 90: 221-25. 